
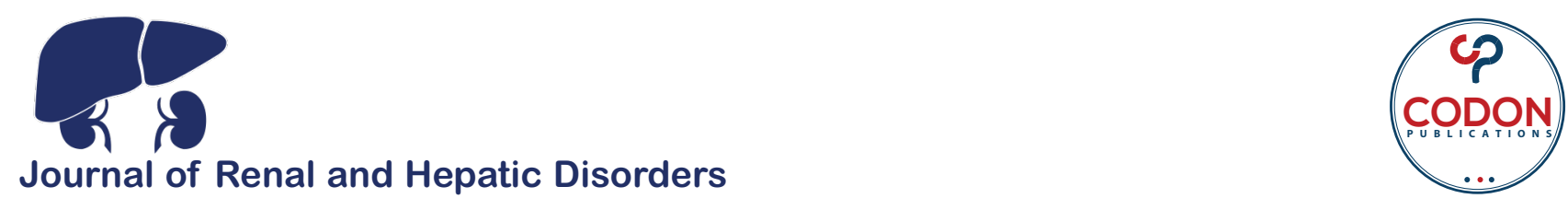

COMMENTARY

\title{
Direct-Acting-Antivirals Anti-hepatitis C Virus in Renal Transplant Patients: Relevance of Pharmacologic Interaction
}

\author{
Maurizio Salvadori ${ }^{1}$ and Aris Tsalouchos ${ }^{2}$
}

${ }^{1}$ Department of Transplantation Renal Unit, Careggi University Hospital, Florence, Italy; ${ }^{2}$ Division of Nephrology and Dialysis Unit, Saints Cosmas and Damian Hospital, Pescia, Italy

\begin{abstract}
Renal transplantation in patients affected by hepatitis C virus (HCV) infection has been a serious problem because of the use of immunosuppressants. HCV virus may be more aggressive in both the liver and the kidney. Several posttransplantation pathologies are known to be ascribed to the $\mathrm{HCV}$ virus. Virus eradication has been historically attempted with interferon (IFN) and ribavirin with poor results. In addition, IFN given posttransplantation may cause severe acute rejection. The introduction of direct antiviral agents (DAA) has revolutionized the treatment, and now it is possible to treat renal transplant patients with these agents leading to a HCV-free status in 3 months without the use of IFN. The major problem caused by these agents is their interference with the immunosuppressive agents. The pharmacokinetics of DAA and immunosuppressants often meet the same metabolic pathways and use the same cytochromes or proteic complexes. In some cases, this may lead to high or low immunosuppressant levels with the risk of rejection. In other cases, the DAAs are interested and they may be increase or decrease in a dangerous way. Therefore, a strict monitoring is always recommended.
\end{abstract}

Keywords: direct antiviral agents; HCV-related diseases; immunosuppressants; metabolic pathways; posttransplant complications

Received: 30 June 2020; Accepted after Revision: 23 July 2020; Published: 03 August 2020

Author for correspondence: Maurizio Salvadori, MD, Professor, Department of Transplantation Renal Unit, Careggi University Hospital, Viale Pieraccini 18, Florence 50139, Italy. Tel.: +39-55-597151. Email: maurizio.salvadori1@gmail.com

How to cite: Salvadori M et al. Direct-Acting-Antivirals (DAA) Anti HCV in Renal Transplant Patients: Relevance of Pharmacologic Interaction. J Ren Hepat Disord. 2020;4(2):29-33.

Doi: https://doi.org/10.15586/jrenhep.v4i2.79

Copyright: Salvadori M et al.

License: This open access article is licensed under Creative Commons Attribution 4.0 International (CC BY 4.0). http://creativecommons.org/

\section{Introduction}

Carta et al. published an interesting article on the use of some direct antiviral agents (DAAs) in renal transplant (RT) recipients affected by hepatitis $\mathrm{C}$ virus $(\mathrm{HCV})$ infection.

The issue is relevant and presents several aspects that need to be highlighted.

\section{Clinical Problems of HCV in RT Patients}

The persistence of $\mathrm{HCV}$ infection after RT is a severe risk factor for graft and patient survival. Complications may involve the liver or the kidney. 


\section{Liver disease}

The immunosuppression is associated with an increase in viral replication and with a progression of hepatic fibrosis (1). The same study documented that the evolution toward cirrhosis was $21.4 \%$ in transplant patients versus $3.6 \%$ in nontransplant patients.

\section{Renal disease}

1. Secondary infections

RT patients $\mathrm{HCV}+$ have a higher incidence of systemic infections, in particular affecting the central nervous system and the respiratory tract. These infections in these patients represent the second most common cause of patient deaths after hepatic disease (2).

2. Posttransplant diabetes mellitus (NODAT)

In one meta-analysis on 30,099 RT patients, the prevalence of diabetes mellitus was higher in $\mathrm{HCV}+$ patients (3).

3. Lymphoproliferative disorders

Several studies documented an increase of lymphoproliferative disorders in $\mathrm{HCV}+\mathrm{RT}$ patients (4).

4. Glomerulonephritis

$\mathrm{HCV}$ with associated cryoglobulinemia frequently causes membranoproliferative glomerulonephritis (MPGN) after RT (5). In this study, MPGN was found in 45.4\% of RT patients who were $\mathrm{HCV}+\mathrm{HCV}+$ is also associated with membranous nephropathy (MN) after RT (6). Both MPGN and MN can be ascribed to the deposition of immunocomplexes containing viral RNA (7).

5. Transplant glomerulopathy

One study from the Boston study group (8) studied $29 \mathrm{HCV}+\mathrm{RT}$ patients and found that transplant glomerulopathy (the marker of chronic rejection) developed significantly earlier posttransplantation in $\mathrm{HCV}+$ RT patients with respect to $\mathrm{HCV}-$ patients $(\mathrm{P}=0.02)$. The authors documented an overlapping of chronic humoral rejection, $\mathrm{HCV}$ infection, and thrombotic microangiopathy.

Finally, it is important to remember the high incidence of acute rejection in transplant patients receiving interferon (IFN) (9).

All these findings support the relevance of treating $\mathrm{HCV}$ infection in RT patients and the need to find alternative and more effective therapies with respect to IFN.

\section{DAA-Based Therapies}

The improved knowledge of the vital cycle of HCV and of the virus structure and its proteins allowed the development of highly efficient DAA (Figure 1).

To date, the DAAs may be divided into four classes according to the mechanism of action (Table 1). The first DAAs for the treatment of $\mathrm{HCV}$ were the protease inhibitors against NS3/SA, such as telaprevir and boceprivir $(10,11)$. These drugs are used for the treatment of genotype 1 in association with IFN and ribavirin. In 2013, three new DAAs were approved in the United States: simeprivir (IP-NS3/NS4A), daclatasvir (inhibitor of NS5A), and sofosbuvir (inhibitor of polymerase NS5B). The use of these DAAs allowed for avoiding the use of IFN. New strategies in the use of DAAs have been the use of combinations of DAAs (12), such as sofosbuvir and ledipasvir. More recently, new DAAs have been added, such as elbasvir, glecaprevir, ritonavir, ombitasvir, dasabuvir, and voxilaprevir $(13,14)$.

The introduction of these drugs allowed for obtaining efficacy against all genotypes, to reduce the duration

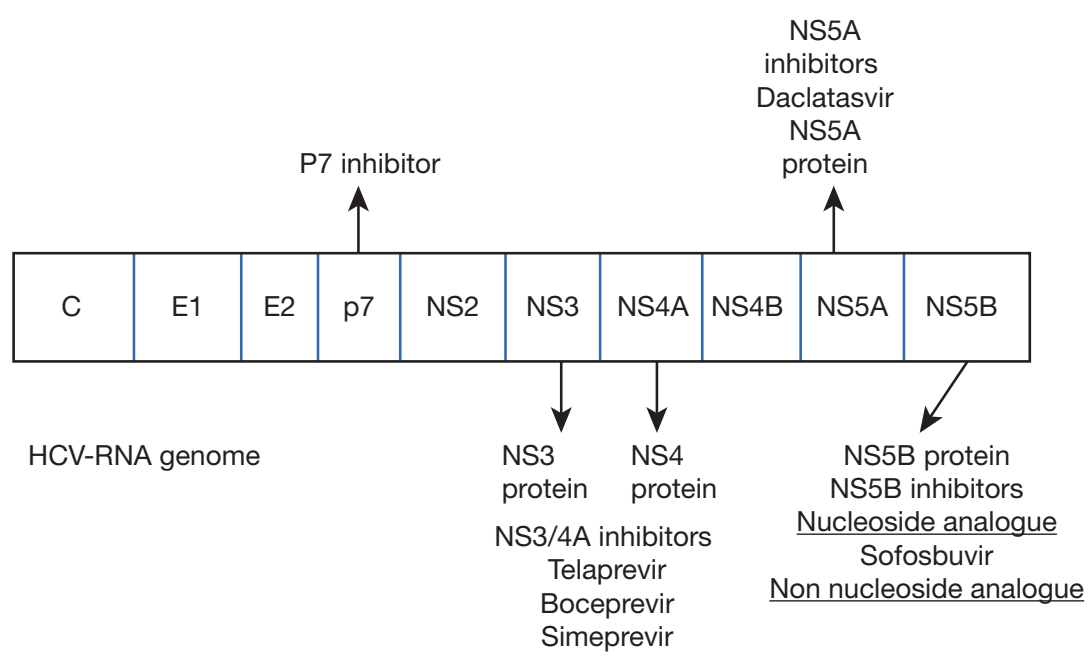

Figure 1. Development of new drugs for HCV infection. HCV, hepatitis C virus. 
Table 1: The four classes of DAAs.

\begin{tabular}{|l|l|l|}
\hline The four classes of DAAs & \multicolumn{2}{|c}{ Mechanism of action } \\
\hline $\begin{array}{l}\text { NS3/4A protease inhibitors } \\
\text { (PIs) }\end{array}$ & $\begin{array}{l}\text { Block a viral enzyme (protease) that enables } \\
\text { the hep C virus to survive and replicate in } \\
\text { host cells }\end{array}$ & $\begin{array}{l}\text { - Glecaprevir }(1-6) \\
\text { - Paritaprevir }(1,4) \\
\text { - Voxilaprevir }(1-6) \\
\text { - Grazoprevir }(1,3,4)\end{array}$ \\
\hline $\begin{array}{l}\text { Nucleoside and nucleotide } \\
\text { NS5B polymerase inhibitors }\end{array}$ & $\begin{array}{l}\text { Target the hep C virus to stop it from } \\
\text { replicating itself in the liver, thereby } \\
\text { blocking the virus from multiplying }\end{array}$ & - Sofosbuvir $(1-4)$ \\
\hline $\begin{array}{l}\text { NS5A inhibitors } \\
\text { Block a virus protein, NS5A, that HCV } \\
\text { needs to reproduce and for various stages } \\
\text { of infection }\end{array}$ & $\begin{array}{l}\text { - Ombitasvir }(1,4) \\
\text { - Pibrentasvir }(1-6)\end{array}$ \\
\hline $\begin{array}{l}\text { Nonnucleoside NS5B } \\
\text { polymerase inhibitors }\end{array}$ & $\begin{array}{l}\text { Stop HCV from reproducing by inserting }(3) \\
\text { themselves into the virus so that other } \\
\text { pieces of the hep C virus cannot attach to it }\end{array}$ & - Elbasvir $(1,4)$ \\
\hline
\end{tabular}

DAA, Direct-Acting-Antivirals; HCV, hepatitis C virus; hep C, hepatitis C.

of treatment, and to increase the safety and efficacy of the treatment (15).

The new KDIGO guidelines recommend that all patients with $\mathrm{HCV}$ who are candidates for kidney transplantation should be considered for DAA therapy, either before or after transplantation. The same recommendation applies to $\mathrm{HCV}$ candidates with a living donor (16).

\section{Pharmacological Interactions}

Pharmacokinetic interactions are the most important, primarily because of the role of cytochrome P450 (CYP450). The interactions with glycoprotein $\mathrm{P}(\mathrm{P}$-gp) are also important in limiting the drug bioavailability $(17,18)$.

The use of drugs inducing CYP450 or P-gp carries the risk of reducing the DAA concentrations. On the other hand, the use of the protein inhibitor, NS3-4A, is contraindicated in patients with severe liver disease. Similarly, the use of the polymerase inhibitor, sofosbuvir, is not indicated in patients with estimated glomerular filtration rate (eGFR) $<30 \mathrm{~mL} /$ $\mathrm{min} / 1.73 \mathrm{~m}^{2}$ because of its renal elimination (19).

In addition to inhibiting cytochrome CYP3A, cyclosporine (CyA) also inhibits the organ anion transporter family $1 \mathrm{~B} 1 / 3$ (OATP1B1/3), the breast cancer resistance protein (BCRP), and P-gp. As a consequence, its administration with a protease inhibitor IPNSA3-4A is not recommended because of the increase in blood CyA. On the contrary, the administration of simeprevir with tacrolimus (TAC) causes only a small decrease of the latter and requires monitoring $(20,21)$.

The new combinations with an IPNS3-4A as grazoprevirelbasvir or glecaprevir-pibrentasvir or sofosbuvirledipasvir-voxilaprevir may cause a mild TAC modification and require monitoring (22-24).

No data are available for the inhibitors of mammalian target of rapamycin (mTORIs).

Daclatasvir and sofosbuvir may be safely administered together with TAC and mTORIs (25).

The association between ombitasvir-paritaprevirritonavir and the immunosuppressants may be dangerous because ritonavir causes inhibition of CYP3A4 and of P-gp. This may cause an increase of the calcineurin inhibitors and of the mTORIs. In one study (26), CyA doses were reduced to one-fifth and TAC doses were reduced to $0.5 \mathrm{mg} /$ week.

Table 2 shows the modifications of immunosuppressant doses in patients receiving DAA.

In conclusion, the availability of new IFN-free DAA offers the possibility of efficiently treating RT patients with $\mathrm{HCV}$ infection.

The possible important interactions between these drugs and the immunosuppressants often require strict monitoring to reduce the risks of rejection or immunosuppressantsrelated toxicity. 
Table 2. Adjustments and monitoring of immunosuppressants in patients on treatment with DAA.

\begin{tabular}{|c|c|c|c|c|c|c|}
\hline Antiviral & Azathioprine & Mycophenolic acid & CyA & TAC & Sirolimus & Everolimus \\
\hline Sofosbuvir & - & - & - & - & - & - \\
\hline Simeprevir & - & - & Not to be given & Monitoring & Monitoring & Monitoring \\
\hline Daclatasvir & - & - & - & - & - & - \\
\hline $\begin{array}{l}\text { Sofosbuvir/ } \\
\text { Ledipasvir }\end{array}$ & - & - & Monitoring & Monitoring & Monitoring & Monitoring \\
\hline $\begin{array}{l}\text { Paritaprevir/ } \\
\text { Ombitasvir/ } \\
\text { Ritonavir }\end{array}$ & - & Monitoring & Monitoring & Monitoring & Monitoring & Monitoring \\
\hline $\begin{array}{l}\text { Sofosbuvir/ } \\
\text { Velpatasvir }\end{array}$ & - & - & Not to be given & Monitoring & Monitoring & Monitoring \\
\hline $\begin{array}{l}\text { Sofosbuvir/ } \\
\text { Velpatasvir/ } \\
\text { Voxilaprevir }\end{array}$ & - & - & Not to be given & Monitoring & Monitoring & Monitoring \\
\hline $\begin{array}{l}\text { Grazoprevir/ } \\
\text { Elbasvir }\end{array}$ & - & - & $?$ & $?$ & $?$ & $?$ \\
\hline
\end{tabular}

-No clinical interaction.

DAA, Direct-Acting-Antivirals; CyA, cyclosporine; TAC, tacrolimus.

\section{Conflict of Interest}

The authors declare no potential conflicts of interest with respect to research, authorship, and/or publication of this article.

\section{References}

1. Zylberberg H, Nalpas B, Carnot F, Skhiri H, Fontaine H, Legendre C, et al. Severe evolution of chronic hepatitis $\mathrm{C}$ in renal transplantation. A case control study. Nephrol Dial Transplant. 2002;17 (1):129-33. http://dx.doi.org/10.1093/ndt/17.1.129

2. Mitwalli AH, Alam A, al-Wakeel J, al Suwaida K, Tarif N, Schaar TA, et al. Effect of chronic viral hepatitis on graft survival in Saudi renal transplant patients. Nephron Clin Pract. 2006;102 (2):c72-80. http://dx.doi.org/10.1159/000089090

3. Fabrizi F, Martin P, Dixit V, Bunnapradist S, Kanwal F, Dulai G. Post-transplant diabetes mellitus and HCV seropositive status after renal transplantation. Meta-analysis of clinical studies. Am J Transplant. 2005;5(10):2433-40. http://dx.doi. org/10.1111/j.1600-6143.2005.01040.x

4. Burra P, Buda A, Livi U, Rigotti P, Zanus G, Calabrese F, et al. Occurrence of post-transplant lymphoproliferative disorders among over thousand adult recipients: Any role for hepatitis C infection? Eur J Gastroenterol Hepatol. 2006;18(10):1065-70. http://dx.doi.org/10.1097/01.meg.0000231752.50587.ae

5. Cruzado JM, Carrera M, Torras J, Grinyó JM. Hepatitis C virus infection and de novo glomerular lesions in renal allografts. Am J Transplant. 2001;1(2):171-8. http://dx.doi. org/10.1034/j.1600-6143.2001.10212.x
6. Morales JM, Pascual-Capdevila J, Campistol JM, FernandezZatarain G, Munoz MA, Andres A, et al. Membranous glomerulonephritis associated with hepatitis $\mathrm{C}$ virus infection in renal transplant patients. Transplantation. 1997;63(11):1634-9. http:// dx.doi.org/10.1097/00007890-199706150-00017

7. Perico N, Cattaneo D, Bikbov B, Remuzzi G. Hepatitis C infection and chronic renal diseases. Clin Am Soc Nephrol. 2009;4(1):207-20. http://dx.doi.org/10.2215/CJN.03710708

8. Baid-Agrawal S, Farris AB, Pascual M, Mauiyyedi S, Farrell ML, Tolkoff-Rubin N, et al. Overlaping pathways to transplant glomerulopathy: Chronic humoral rejection, hepatitis $\mathrm{C}$ infection and thrombotic microangiopathy. Kid Int. 2011;80(8):879-85. http://dx.doi.org/10.1038/ki.2011.194

9. Baid S, Tolkoff-Rubin N, Saidman S, Chung R, Williams WW, Auchincloss $\mathrm{H}$, et al. Acute humoral rejection in hepatitis C-infected renal transplant recipients receiving antiviral therapy. Am J Transplant. 2003;3(1):74-8. http://dx.doi. org/10.1034/j.1600-6143.2003.30113.x

10. Aghemo A, de Francisco R. New horizons in hepatitis C antiviral therapies with direct-acting antiviral. Hepatology. 2013;58(1):428-38. http://dx.doi.org/10.1002/hep.26371

11. Yau A, Yoshida E. Hepatitis C drugs: The end of the pegylated interferon era and the emergence of all-oral interferon-free antiviral regimens: A concise review. Can J Gastroenterol Hepatol. 2014;28(8):445-51. http://dx.doi.org/10.1155/2014/549624

12. AASLD-IDSA. American Association for the Study of Liver Diseases/Infectious Disease Society of America joint guidelines, recommendations for testing, managing, and treating hepatitis $\mathrm{C}$ [Internet]. [cited 2020 Feb 26]. Available from: www.hcvguidelines.org

13. Belga S, Doucette KE. Hepatitis $\mathrm{C}$ in non-hepatic solid organ transplant candidates and recipients: A new horizon. World $\mathbf{J}$ 
Gastroenterol. 2016;22(4):1650-63. http://dx.doi.org/10.3748/ wjg.v22.i4.1650

14. Salvadori M, Tsalouchos A. Hepatitis C and renal transplantation in era of new antiviral agents. World J Transplant. 2018;8(4):84-96. http://dx.doi.org/10.5500/wjt.v8.i4.84

15. Jadoul M, Berenguer MC, Doss W, Fabrizi F, Izopet J, Jha V, et al. Executive summary of the 2018 KDIGO hepatitis C in CKD guideline: Welcoming advances in evaluation and management. Kidney Int. 2018;94(4):663-73. http://dx.doi. org/10.1016/j.kint.2018.06.011

16. KDIGO clinical practice guideline on the evaluation and management of candidates for kidney transplantation. Transplantation. 2020;104(4S):S57-8.

17. Dresser GK, Spence JD, Bailey DG. Pharmacokineticpharmacodynamic consequences and clinical relevance of cytochrome P450 3A4 inhibition. Clin Pharmacokinet. 2000;38(1):41-57.http://dx.doi.org/10.2165/00003088-20003801000003

18. Marquez B, van Bambeke F. ABC multidrug transporters: Target for modulation of drug pharmacokinetics in drug-drug interactions. Curr Drug Targets. 2011;12(5):600-20. http://dx. doi.org/10.2174/138945011795378504

19. European Association for the Study of the Liver. EASL recommendations on treatment of hepatitis C 2018. J Hepatol. 2018. http://dx.doi.org/10.1016/j. jhep.2018.03.026

20. Hill L. Hepatitis C virus direct-acting antiviral drug interactions and use in renal and hepatic impairment. Top Antivir Med. 2015;23(2):92-6.

21. Ouwerkerk-Mahadevan S, Snoeys J, Peeters M, BeumontMauviel M, Simion A. Drug-drug interactions with the
NS3/4A protease inhibitor simeprevir. Clin Pharmacokinet. 2016;55(2):197-208. http://dx.doi.org/10.1007/s40262-015-0314-y

22. Colombo M, Aghemo A, Liu H, Zhang J, Dvory-Sobol H, Hyland R, et al. Treatment with ledipasvir-sofosbuvir for 12 or 24 weeks in kidney transplant recipients with chronic hepatitis C virus genotype 1 or 4 infection: A randomized trial. Ann Intern Med. 2017;166(2):109-17. http://dx.doi.org/10.7326/M16-1205

23. Reau N, Kwo PY, Rhee S, Brown RS Jr, Agarwal K, Angus P, et al. Glecaprevir/pibrentasvir treatment in liver or kidney transplant patients with hepatitis $\mathrm{C}$ virus infection. Hepatology. 2018;68(4):1298-307. http://dx.doi.org/10.1002/hep.3004

24. Fernández-Ruiz M, Polanco N, García-Santiago A, Muñoz R, Hernández AM, González E, et al. Impact of anti-HCV direct antiviral agents on graft function and immunosuppressive drug levels in kidney transplant recipients: A call to attention in the mid-term follow-up in a single-center cohort study. Transplant Int. 2018;31(8):887-99. http://dx.doi.org/10.1111/tri.13118

25. Kwo PY, Badshah MB. New hepatitis C virus therapies: Drug classes and metabolism, drug interactions relevant in the transplant settings, drug options in decompensated cirrhosis, and drug options in end-stage renal disease. Curr Opin Organ Transplant. 2015;20(3):235-41. http://dx.doi.org/10.1097/MOT. 0000000000000198

26. Kwo PY, Mantry PS, Coakley E, Te HS, Vargas HE, Brown R $\mathrm{Jr}$, et al. An interferon free antiviral regimen for $\mathrm{HCV}$ after liver transplantation. N Engl J Med. 2014;371(25):2375-82. http://dx. doi.org/10.1056/NEJMoa1408921 